\title{
Influence of the Driver Style difference in the Acceleration Process on the Energy Consumption of the EV Bus Ying YAN $^{1}$, Ye-Cheng FAN ${ }^{2}$ \\ ${ }^{1}$ Tianjin University of Technology and Education, Tianjin, China \\ ${ }^{2}$ Freescale Semiconductor China Ltd,Tianjin,China \\ KEYWORD: Energy consumption; Accelaration process ;Driver style
}

ABSTRACT: The relationship between the difference of the driver behavior and energy consumption in the same bus line was studied through analyzing the acceleration process of the driving cycles in order to solve the problem that the practical benefits in endurance mileage of the electric buses differed a lot. It shows that $47 \%$ of the energy was consumed in the process of out station and the difference reached $28.9 \%$ between the drivers. The essential reason of the difference was the deviaton of the motor operating path in the efficiency plane which was the result of accelerator pedal used in different way. The end speed of acceleration and the distribution of the accelerator pedal was useful to experss the driver style. An effective management to the motor operating path in the out station process is very helpful to the improvement of the whole energy consumption besides the minimization of the acceleration dispersion.

\section{Introduction}

The research of decreasing energy consumption and extension of the driving range is a key problem to the development of the pure electric vehicle(EV). However, due to inappropriate driver behaviors the practical endurance mileage of the electric buses are significantly reduced.

Numerous studies have shown that driving style (DS) has important implications on vehicle fuel consumption. Gonder conducted experiments on a light-duty vehicle and found that different DS can generate difference of approximately $30 \%$ in fuel consumption in the urban driving cycle. The difference can reach $20 \%$ in the high-speed way driving cycle. They also believe that by changing DS, aggressive drivers can reduce fuel consumption by $20 \%$, whereas mild drivers can decrease consumption by $5-10 \%^{[1]}$. Sivak and Schoettle discovered through an investigation that among the fuel-saving technologies of light-duty vehicles through which drivers can make strategic decisions, the method of changing DS generates the best fuel-saving result ${ }^{[2]}$. Professor Chris Bingham found that the net energy consumed difference can reach 32\% between drivers even they drove the same test EV car to finish the same driving cycles without any additional driving request. It showed that the management of driver behavior could provide the most significant energy benefits in all technical means ${ }^{[3-5]}$. The dynamics in real world driving was much more than the standard ones such as NEDC. During real world driving, the change rate of the accelerator pedal was more complicate which is the reflection of the driver operation patterns. The conclusion pointed out that it is better to impove the economy and the battery life by changing the pedal gently ${ }^{[6]}$. The similar view can be found in ${ }^{[7-10]}$.

It has been proved that the energy consumption was greatly affected by the driver behaviors. This paper was focused on the relationship between the difference of the driver behavior and the energy consumption of the accelaration process under the same bus road conditon.

\section{Data acquisition}

There were 26 bus stations and 44 crosses of the No.600 EV bus in Tianjin as the research object which means frequent stop-go. The bus line was shown in Fig.1.

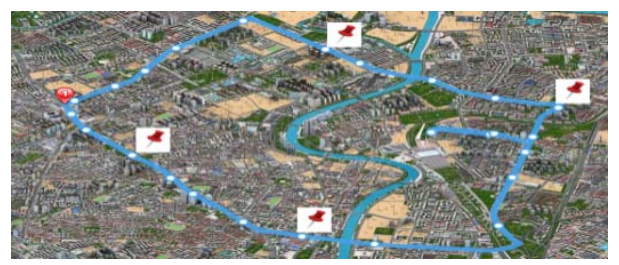

Figure 1. The No.600 bus line 
The longest distance between two adjacent stations was $982 \mathrm{~m}$ while the shortest one was only $65 \mathrm{~m}$ and $200 \mathrm{~m}$ was the average value including crosses. The traffic condition could be divided into two parts based on the time consumed of one driving cycle: smoothe traffic and the opposite such as the rush hour in the morning per working day. The selected driving fragment of the driving cycles should reflect the internal driving trend of the driver which means the driver could operate the bus as his will without any other limits. By comprehensive consideration, the principle of data sample selection was shown as Tab.1.

Table.1 Principle of data selection

\begin{tabular}{c|c}
\hline Parameter & Value \\
\hline Stations distance & $>300$ meters \\
Consuming time & $<3400$ seconds \\
Date & working day \\
Time zone & $10: 00 \mathrm{~h} \sim 11: 30 \mathrm{~h} ; 20: 00 \mathrm{~h} \sim 22: 30 \mathrm{~h}$ \\
\hline
\end{tabular}

Five drivers named A to E were selected as the research object who had driven the same EV bus over 2 years under the same bus line and Totally over 100,000 km driving cycles data was acquired through vehicle data acquisition system.

\section{Ds variation in acceleration process}

\subsection{End speed of acceleration}

The bus out operation was the typical acceleration operation besides important driving fragment of the driver behavior. A whole bus out process was defined by the speed curve from the init value to the end of speed(Vend) which the init value was usually set at $0 \mathrm{~km} / \mathrm{h}$. Thus, the energy consumption and the information of the driver behavior of the bus out process was directly influenced by the $V_{\text {end }}$ which means the end of the bus out process. The $V_{\text {end }}$ depends on two aspects,one is the traffic condition of the bus line, and the other has relationship with the driver internal speed respect which is an important parameter in the evaluation index of the DS.

It was shown in Fig.2 to compare the energy consumed and the $V_{\text {end }}$ for all the research drivers in the bus out process at the same bus station. The higher the $V_{\text {end }}$ was, the higher the energy was consumed and the more energy variation was between all the drivers. More $32.7 \%$ energy was needed to operate the bus to reache $36 \mathrm{~km} / \mathrm{h} \mathrm{V}_{\text {end }}$ for the driver $\mathrm{E}$ compared to the driver $\mathrm{C}$. The driver $\mathrm{C}$ has the best bus out driving behavior.

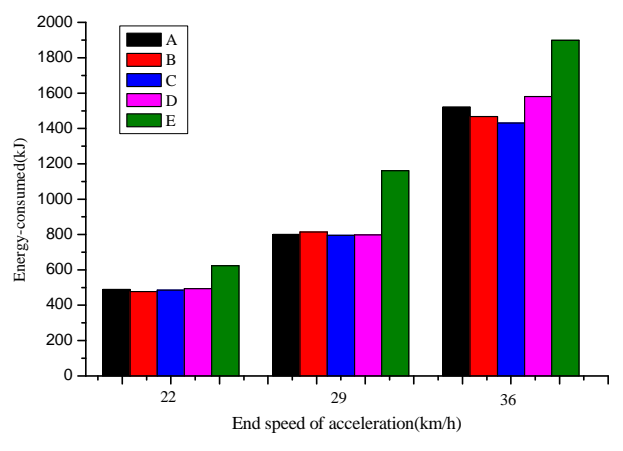

Figure 2. Energy-consumed in different drivers

More details can be obtained in Fig.3. The energy consumption differed a lot when the bus reach the same $V_{\text {end }}$ between all the reseach objetcts. When the $V_{\text {end }}$ was smaller than $25 \mathrm{~km} / \mathrm{h}$, all the five slope of curves almost were equal. It shows that all the drivers operated the bus under similar acceleration strategy and the energy variation was pretty small. When the $V_{\text {end }}$ became higer which means good traffic condition,the energy difference became more significant since the DS variation. Different acceleration strategy was realised by the drivers even for the same speed respect. It was shown that the whole acceleration process can be divided into two parts: low speed zone and 
high speed zone. The turning point happened in the speed zone $(25,30) \mathrm{km} / \mathrm{h}$. After the turning point, the slope of curve became much sharper which means more energy was consumed when the same unit vehicle speed was reached. It is feasible to minimize the energy consumption reaching the $V_{\text {end }}$ by adjusting the bus out acceleration strategy to optimize the slope of curve .

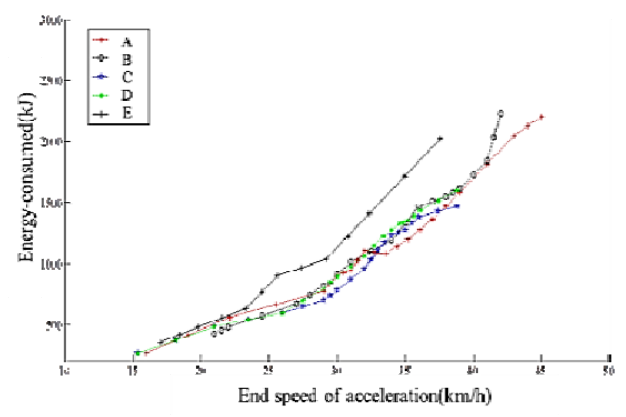

Figure 3. Energy consumption under different bus out $\mathrm{V}_{\text {end }}$

\subsection{Bus out process distance}

The relationship between the bus out distance with the energy consumption was shown in Fig .4. It can be found that the longer distance the bus out process took,the less energy was consumed for the unit distance.Because when the bus runs at lower speed, the motor efficience is much worse which means energy waste. As the bus speed clumbing up,the motor efficience went into high value zone.The bus out energy consumption trends to stabilization after $138 \mathrm{~m}$ bus out distance under driver A,B,C's operation while driver E wasted maximum energy as similar performance shown in Fig.2.

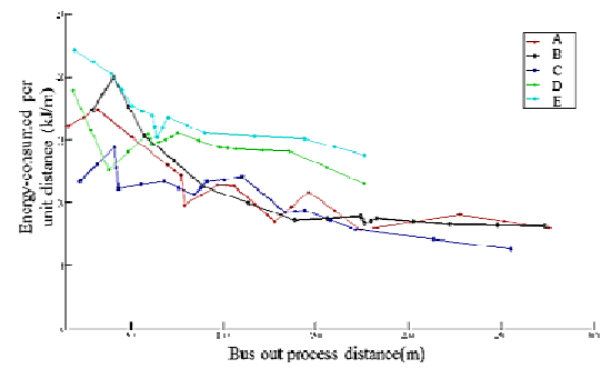

Figure 4. Bus out process distance

\subsection{Distribution of the accelerator pedal}

The bus out process is a continuous acceleration driving cycle fragment with the occupation of the accelerator pedal and no gearshit operation since the EV bus configuration. The working path of the drive motor was decided by the usage of the accelerator pedal depending on the DS which would cause the variation of the motor efficience. The distribution of the accelerator pedal was shown in Fig.5.

The best driver $C$ trends to use soft pedal to finish the acceleration process with only $24.17 \%$ deep pedal ratio. On the contrast, driver $\mathrm{D}$ and $\mathrm{E}$ are likely to operate the bus under high acceleration speed. The accelerator pedal was much more deeply used under driver E's operation with $73.38 \%$ distribution belonging to $(80 \%, 100 \%)$. The more the accelerator was used deeply, the worse the energy performance was. The conclusion was consistent with the analysis result aboved. 


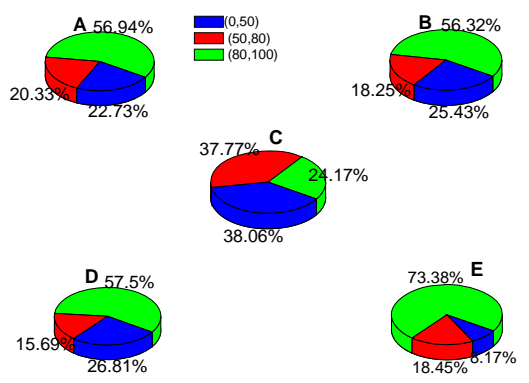

Figure 5. Distribution of the accelerator pedal

\subsection{Bus out time-consuming}

The bus out process takes up a great proportion in the whole bus driving cycle since 26 bus station and 44 crosses. The average bus out time-consuming of one cycle was list in Tab.2 besides other parameters mentioned above. It can be found that the least time in one driving cycle was consumed to finish the bus out process by driver $\mathrm{C}$ since the time ratio was only $16.6 \%$. It can be concluded that the $V_{\text {end }}$ of driver $C$ is smaller than others and did not trend to drive the bus under high speed which resulted in less bus out energy-consumed and drive cycle energy-consumed compared to other drivers' performance. On the contrary, driver E took the least time and the shortest bus out distance to finish the acceleration operation with the worst energy performance. It can be speculated that the driver E trends to operate the bus under high acceleration speed to reach the $V_{\text {end }}$ which usually would make extra energy waste.

Table 2. The bus out parameters list

\begin{tabular}{cccccccc}
\hline Serial & $\begin{array}{c}\text { Bus out } \\
\text { time- } \\
\text { consuming } \\
(\mathrm{s})\end{array}$ & $\begin{array}{c}\text { Bus out } \\
\text { time } \\
\text { ratio } \\
(\%)\end{array}$ & $\begin{array}{c}\text { Bus out } \\
\text { process } \\
\text { distance } \\
(\mathrm{m})\end{array}$ & $\begin{array}{c}\text { Bus out } \\
\text { distance } \\
\text { ratio } \\
(\%)\end{array}$ & $\begin{array}{c}\text { Bus out } \\
\text { energy } \\
\text { consumed } \\
(\mathrm{kJ})\end{array}$ & $\begin{array}{c}\text { Whole } \\
\text { energy } \\
\text { consumed } \\
(\mathrm{kJ})\end{array}$ & $\begin{array}{c}\text { Bus out } \\
\text { energy } \\
\text { ratio } \\
(\%)\end{array}$ \\
\hline A & 740.9 & $18.6 \%$ & 4403.7 & $26.4 \%$ & 43228.6 & 85710.3 & $50.4 \%$ \\
B & 719.4 & $22.3 \%$ & 4764.0 & $28.5 \%$ & 42676.9 & 82022.2 & $52.0 \%$ \\
C & 767.7 & $16.6 \%$ & 3916.8 & $23.5 \%$ & 37084.6 & 78649.3 & $47.2 \%$ \\
D & 611.5 & $18.2 \%$ & 2948.5 & $17.7 \%$ & 44521.5 & 89414.1 & $49.8 \%$ \\
E & 615.6 & $22.7 \%$ & 2930.2 & $17.5 \%$ & 47792.4 & 94970.1 & $50.3 \%$ \\
\hline
\end{tabular}

It was worthy for more attention that the overall bus out energy ratio was almost close to $50 \%$ with the 28.9\% maximum deviation of the bus out energy-consumed between all the drivers. It is an important means and measure to improve the EV bus energy performance based on bus out energy management.

\section{Summary}

The driver behavior parameters in the bus out process were discussed in this paper in order to find out the reason for the energy variation between different drivers. The end speed of acceleration is an important parameter of the DS. The energy-consumed difference of the bus out process can reach $28.9 \%$ since the variation of the DS. It is found that the energy-consumed difference was caused by the end speed of acceleration besides the distribution of the accelerator pedal which finally determined the working path of the drive motor in the efficience plane. It is workable to improve the EV bus energy performance through the bus out energy management since its $47 \%$ considerable proportion.

\section{Acknowledgments}

This Study is supported by the Project of National Nature Science Foundation of China (Grant 51307119) from National Nature Science Foundation Committee of China. 


\section{References}

1.Gonder, J., Earleywine, M., Sparks, W. Analyzing vehicle fuel saving opportunities through intelligent driver feedback. SAE International Journal of Passenger Cars - Electronic and Electrical Systems, 2012(2),101-110

2.Sivak, M., Schoettle, B.,Eco-driving: Strategic, tactical, and operational decisions of the driver that influence vehicle fuel economy. Transp. 2012,Policy 22,96-99

3.Chris Bingham, Power Energy Storage Technologies and Energy Management.3th Advanced Engine Control Symposium,TianJin,2010

4.Hongjie Ma, Hui Xie , Denggao Huang, Shuo Xiong.Effects of driving style on the fuel consumption of city buses under different road conditions and vehicle masses,Transportation Research Part D,41 (2015) 205-216

5.Ma Hongjie,Xie Hui,Chen Shuangxi, Yan Ying,Huang Denggao. Effects of Driver Acceleration Behavior on Fuel Consumption of City Buses,SAE Technical Paper 2014-01-0389.Detroit, USA. April 8-10, 2014

6.C. Cheng, A. McGordon. A Model to Investigate the Effects of Driver Behaviour on Hybrid Vehicle Control,The 25th International Battery, Hybrid and Fuel Cell Electric Vehicle Symposium \& Exposition ,2010

7.Matthew G. Shirk, Benjamin M. Geller. Factors Affecting the Fuel Consumption of Plug-In Hybrid Electric Vehicles,The 25th International Battery, Hybrid and Fuel Cell Electric Vehicle Symposium \& Exposition ,2010

8.Yun-Jie Hsu, Jung-Ho Cheng, Yi-Hsiang Yang. Effect of Vehicle Control Unit Parameters on Electric Vehicle Driving Operation Responses,The 25th International Battery, Hybrid and Fuel Cell Electric Vehicle Symposium \& Exposition,2010

9.Xuan Liu,Hui Xie.The Effects of Bus Driver's Behavior on Fuel Consumption and Its Evaluation Indicator, Automotive Engineering,2014(11),1321-1326

10.Hui Xie, Shuangxi Chen. Analysis on the Influence of Driver Deceleration Behavior During Bus Stop on Fuel Consumption, Journal of Tianjin University,2015(12),1091-1098 